MANIFESTO SERESTEIRO， SERES TEIRO MANIFESTO E UM ROTEIRO PARA A PERFORMANCE DE UM CANC I ONE I RO

Resumo

Trata-se de uma reflexão, seguida de um roteiro de pretensões dramatúrgicas que reúne histórias, pensamentos e devaneios entremeados por canções compostas no decorrer do processo de pesquisa de doutoramento que dá origem a este artigo. A elaboração poética é tomada como materialidade a partir da qual é possível transitar pelo imaginário seresteiro como uma espécie de avaliação criativa de sua tradição e proposição de outros destinos.

Palavras-chave:

Seresta. Poética do imaginário. Dramaturgia expandida. 


\section{MANIFESTO SERESTEIRO, SERESTEIRO MANI- FESTO E UM ROTEIRO PARA A PERFORMANCE DE UM CANCIONEIRO}

\section{Thales Mendonça (FCP)}

\footnotetext{
Thales Mendonça - Artista da cena, pesquisador e gestor cultural. Possui graduação em Letras (UFPA) com mestrado e doutorado em Artes Cênicas (PPGAC-UFBA) com estágio sanduíche de doutorado na Universidade de Paris X Ouest Nanterre La Défense (França).

thalesbranche@gmail.com
}

Quando decidi que me lançaria na jornada de um doutorado em Artes Cênicas, ou, mais especificamente, na jornada de um doutorado "em demanda da santa seresta" , uma das possibilidades que mais me animava enquanto desafio era a proposta de encerrar o processo de pesquisa com a criação de um espetáculo solo que não sabia muito bem como seria, mas já tinha o título: manifesto seresteiro. Esse espetáculo seria realizado na casa de anfitriões que desejassem recebê-lo e compartilhá-lo com os convidados de sua escolha. Eu, na condição de ator-seresteiro munido de um manifesto, em um primeiro momento apresentaria o espetáculo em si, ao qual se seguiria uma seresta ${ }^{2}$ tal qual aprendi a fazer desde meus tempos primevos. Ou seja,

\footnotetext{
${ }^{1}$ Este texto foi elaborado a partir de um dos capítulos da tese de doutorado intitulada "Em demanda da santa seresta: trajeto criativo a partir de uma seresta primeva às margens do Tapajós", orientada pela Profa. Dra. Sonia Rangel no contexto do Programa de Pós-Graduação em Artes Cênicas da UFBA. ${ }^{2}$ A seresta aqui será abordada fundamentalmente a partir da narração da experiência subjetiva que impulsiona os movimentos criadores discutidos neste texto. De outro modo, de maneira a compor um quadro mínimo de referências bibliográficas ajustadas ao contexto antropológico relacionado ao objeto desta pesquisa, vale considerar o trabalho memorialista do maestro santareno Wilson Fonseca: "Meu Baú Mocorongo: Pesquisas, recordações e reflexões sobre a vida histórica e sociocultural santarena" (2006) e a reconstituição histórica do gênero "modinha", ancestral musical direto da seresta, conforme a contribuição do professor Vicente Sales: "A Modinha no Grão-Pará: estudos sobre ambientação e (re)criação da Modinha no Grão-Pará” (2005).
} 
após um primeiro momento talvez mais solene da apresentação do sonhado manifesto, síntese seresteira das narrativas que compuseram a jornada do doutorado, o rito performativo que propunha se concluiria com a condução festiva de uma seresta. Importante dizer que seresta, conforme aprendi, significa tocar e cantar junto da audiência as canções que fazem a liga das gentes, com atenção constante na escolha do repertório mais amplamente compartilhado, no vai-e-vem da vontade de ferver o corpo com a dança e na revelação, por vezes gradativa e sutil, daqueles que nem se sabiam seresteiros cantadores. De acordo com a proposição do título da jornada de doutorado, se a demanda que se deu foi em nome da santa seresta, devotadamente engajado no sacro-ofício, eu e o violão nos manteríamos a serviço dela até que o último convidado decidisse regressar para casa, ou até quando raiasse o novo dia na casa aberta da vez. É sabido que a seresta tem parte com a lua, e, como rito originalmente noturno, se iniciada à noite, não pode seguir quando é chegado o novo dia.

Rito essencialmente fundado na efemeridade do encontro de natureza performativa, $o$ manifesto seresteiro e seu processo de criação estavam presentes desde o anteprojeto apresentado à seleção do doutorado. No entanto, preciso confessar que, fracassei em partes, pois, no decorrer dos anos em que estive me doutorando, não consegui criar meu manifesto seresteiro conforme a proposta inicial. De outro modo, foi minha orientadora, a professora Sonia, que, em determinado momento da jornada, me fez notar que, se ainda não havia em forma espetacular um manifesto seresteiro, um seresteiro manifesto se pronunciava em mim, especialmente por um movimento criador que no curso da jornada amadureceu em mim: a composição de canções. Parafraseando Drummond, tal movimento considero como o "ganho não previsto" que confirma a intenção amorosa dessa demanda que frutificou em mais de cem composições, que ora abordam diretamente, ora tangenciam o imaginário seresteiro, seja por aspectos musicais da composição da canção (nos quais incluo letra, melodia, gêneros, ritmos e arranjos), seja por provocadores afetivos que inspiraram cada uma das composições. Sendo assim, posso dizer que investir na prática da composição de canções também compôs, do ponto de vista formativo, meu processo de doutoramento.

Em suma, ao fim da jornada do doutorado, talvez eu tenha sido capaz de compor menos um manifesto e mais um cancioneiro a partir de um seresteiro manifesto em mim. As canções que apresento a seguir, quando articuladas por pequenas narrativas extraídas do percurso da jornada, constroem via melodia e poesia o sentido criativo de minha demanda da santa seresta. Desse modo, em vez de um espetáculo solo de pretensões solenemente teatrais, meu manifesto seresteiro se tornou uma espécie de "cantação" de histórias que narra o percurso da demanda por meio das canções, ou seja, uma espécie de performance (por que não?) que aqui apresento na forma de um roteiro de histórias e canções, seguido por um poema em prosa que encerra a performance do manifesto com um manifesto propriamente. Apresento uma versão reduzida do roteiro, o que não é um problema para a compreensão global da proposição original. Tal modificação está incluída como possibilidade desde a proposta inicial de criação do roteiro, ou seja, sua forma é, desde o berço, flexível. O roteiro do manifesto pode e deve ser modificado a cada situação em que "uma casa" ou "uma roda" puder ser aberta à narração de minha demanda da santa seresta. Desse modo, nada mais coerente que adotar essa natureza flexível como princípio da configuração da forma escrita da performance, ainda que a noção de roteiro como recurso de fixação da dramaturgia remonte ao sentido estabilizador da escrita, o que francamente tento desconstruir com um tom narrativo inspirado na oralidade.

Noto que a problematização entre os sentidos da escrita e da oralidade é pertinente na apresentação deste texto, porque interessa à sua contextualização ressaltar a diferença entre a experiência de apreciação do roteiro do manifesto e a performance do mesmo como um fato que não pode ser ignorado. Pessoalmente, compreendo-me como um artista da cena que transita entre diferentes linguagens, mas que tem no corpo em cena seu foco de maior interesse. Assim, quando penso em dar visibilidade 
aos frutos do processo criativo que me levou mais largamente à composição de canções, sinto-me mais engajado em questões da ordem do ato performativo, do que exatamente da especificidade do registro da obra musical, de modo que a fixação das canções obedeceu muito mais à uma tentativa de registrar uma "dicção" pessoal, mais ligada, por assim dizer, à instância performativa coerente ao processo criativo e de pesquisa. Assim sendo, no decorrer do roteiro que aqui apresento, ofereço links para a escuta de registros de áudio das canções, que por um lado expõem minha fragilidade como músico, mas por outro estabelecem, de forma singular, o que chamo de "dicção" como evidente referência ao imaginário ao qual acessei na trejatória da pesquisa eminentemente por meio da oralidade.

"A escrita permanece e estagna, a voz multiplica. Uma se pertence e conserva; a outra expande e destrói [...]. A escrita capitaliza aquilo que a voz dissipa; ela ergue muralhas contra a movência da outra" (ZUMTHOR, 2010, p. 320). É inspirado no sentido da voz segundo a imaginação de Paul Zumthor que proponho a experiência da leitura deste texto como uma verdadeira mediação operada pela dramaturgia (SANCHEZ, p. 19). Assim, a leitura do roteiro de meu "manifesto seresteiro" se propõe como trânsito entre a reflexão advinda de um processo de pesquisa transdisciplinar em artes cênicas e o processo criativo intrinsecamente vinculado àquele. Exercício crítico e criativo são conjugados aqui em um emaranhado propositadamente inespecífico de fabulação, canção e pensamento. E é especificamente a partir dessa aposta que se quer bem-humorada e prazenteira na inespecificidade (GUARRAÑOS, 2014) que reconheço o vínculo deste texto com as discussões acerca do campo expandido.

Para dar cabo a este introito, cabe a reflexão de que, depois de registradas em áudio, é curioso pensar que as canções poderão viver além de mim e de minha demanda, expandindo-se, portanto, e transcendendo a efemeridade do fenômeno performativo a partir do qual eu mais frequentemente as apresento como escolha artística. Nesse sentido, é em respeito e por desejo de reverenciar a efemeridade natural de meu lugar de identidade artística de origem, o teatro, que propus a forma de roteiro como escolha de apresentação do manifesto na tese. Aqui, transito no território de um paradoxo em que ao mesmo tempo em que a narrativa (especialmente oral, ou seja, em performance) da memória da demanda inventa e reinventa os sentidos do trajeto criativo, a forma fixa natural à dinâmica do trato com as canções é conservada através do tempo de modo mais duradouro. De um lado, a proposição dos termos deste roteiro serve como base da liga que se constrói e é assegurada por uma conversa-improviso que garante a singularidade da performance; de outro, o registro em áudio das canções as perenizam no tempo como uma fotografia sonora, um canto parado no ar. Manifesto seresteiro, ou seresteiro manifesto, proponho, com este roteiro, mais uma volta na espiral seresteira ${ }^{3}$, dessa vez por meio de um singelo, mas sincero cancioneiro.

\section{Roteiro}

$\mathrm{Na}$ primeira estação deste manifesto, proponho-me a começar pelo começo e reverenciar o pai. Antes de compreender sequer de forma superficial o sentido de arte ou objeto estético, a música se apresentou em minha vida como parte de um ritual de reunir aqueles com os quais se compartilhava uma relação fervorosa e plena de amor: seresta. Eu, ainda menino, acompanhava meu pai nas serestas que ele fazia com seus amigos em sua terra-mãe Itaituba, também conhecida como "cidade pepita”. Às margens do caudaloso Tapajós, Itaituba é marcada na região como um dos grandes centros da exploração do minério de ouro (daí seu epíteto), o que por um lado movimentou fortemente a economia da cidade durante o auge da exploração, mas por outro provocou danos sociais e ambientais ferozes, tais como o escurecimento das águas verdes de um Tapajós revirado pelas dragas, máquinas de ganância. Apresento uma

\footnotetext{
${ }^{3}$ Com a expressão "espiral seresteira”, refiro-me à forma de organização dos capítulos na tese. Cada capítulo é um ensaio que aborda, de forma independente e singular, a seresta enquanto objeto central da pesquisa.
} 
canção que compus em um momento em que estava distante, além-mar no percurso da jornada. Era a ocasião do aniversário de 60 anos de meu pai, e eu não podia estar fisicamente presente. De meu pequeno exílio, sabia que meu pai, mesmo no dia de seu aniversário, também compartilhava comigo uma estranha sensação de des-lugar dentro do peito. Ele vive em Belém desde o final da década de 70, mas nunca se conformou realmente disso, e é em suas voltas à Itaituba, na contemplação da Castanheira que verdeja duradoura diante da casa de seu saudoso pai no Paraná-Miry, que ele se alimenta das forças mágicas da memória, e então rejuvenesce, se fortalece e cresce. Sendo assim, quis compor como quem pudesse levá-lo para um banho moleque no Tapajós, tal como compartilhamos tantos. Contudo, talvez a distância, talvez a solidão, talvez algo que simplesmente eu nunca saberei me soprou no ouvido uma melodia dolente que tinha como fonte primeira o assovio que meu avô criou para chamar meu pai quando menino. Assim, dedilhando o violão, me veio esta canção:

\section{Canção de remoçar o pai}

Eu quis compor uma canção

Que tivesse um refrão

Cheio de humor e brincadeira

Com seresta e castanheira

E uma rima bem bonita pra sagrada pepita

Eu queria que fosse uma canção alegre

Como uma prece de um moleque

Pra agradar até o pai do pai do pai do pai do meu pai

Vai, canção, cruza o mar feroz

Desata os nós, clareia as águas do Tapajós

Queima, brilha feito um farol, canção

Nina o teu irmão

Reconduz os barcos no tempo-destino de um paraná-menino

Pai, já te disseram que no dia do aniversário Algo de grande acontece em segredo no céu? E se a gente concentrar

Pode até escutar

Serenamente soar a voz de Deus

O tempo deu flor, remoçou ${ }^{4}$
Quando ainda era menino e estava aprendendo a tocar o violão, meu pai repetia, de maneira insistente, uma lição/sermão: o violão deve ser dedilhado. Ele dizia isso principalmente quando reclamava do público dos barzinhos que, para ele, só estavam interessados em ouvir um violão animado às "batidas". Ele também repetia a lição-sermão quando me via demasiadamente engajado no aprendizado de canções de minha fase mais rock'n'roll. Com seu reclame de um violão mais dedilhado, meu pai de alguma forma me ensinava o valor da melancolia bem performada no toque do instrumento. $\mathrm{Na}$ primeira vez em que percebi que fui pego pelo demônio da seresta, havia deixado Salvador durante o semestre em que frequentara a disciplina obrigatória ministrada por minha própria orientadora. Estava passando duas semanas em Belém para trabalhar em um projeto de dança contemporânea, supostamente em colaboração com uma diretora israelense que estava na cidade dirigindo um espetáculo da Companhia de Investigação Cênica, grupo com o qual mantenho relações de colaboração. Houve desentendimentos que não se cabe esmiuçar, e minha missão consistiu basicamente em compor uma canção que fosse cantada por uma das bailarinas durante uma cena do espetáculo. Assim que recebi a tarefa, ofereci meu sono em sacrifício em uma certa noite sem lua e, dedilhando demoradamente o violão, cheguei à um tema que trouxe consigo uma letra que me soava estranha, pois, em um primeiro momento, era como se eu não soubesse muito bem de onde ela vinha. Mais tarde, conectei a melancolia da letra e melodia à tradição da canção seresteira na qual eu já mergulhava:

\section{Lua negra}

Era noite e a lua negra então se revelou Ampliando a escuridão de um peito sofredor E para minha angústia, a minha imensa mágoa

Ela me aconselhava ritos de desamor

Hoje a crueldade faz morada em mim

4 Letra de composição autoral registrada em caderno pessoal de anotações. Disponível no canal do YouTube "Manifesto Pitágoras", acessível pelo link: https://youtu.be/_IpLr6Tdo0s. 
Não sou mais capaz de um canto sereno Pássaro ferido eu me abandonei

À ingratidão da sina de cantar toda desilusão

$\mathrm{Ah}$, se ela acordasse enfim

E se ela ouvisse a mim

Cantando o jardim que eu cultivei

Guardado do terror da cidade que não permite o amor

Pudera eu dormir doce também

Te encontraria em sonhos e descansaria enfim $^{5}$

Compartilhando a canção com um bom amigo baiano, grande apreciador do carnaval soteropolitano, recebi como retorno uma bela provocação: ele me pediu, brincando, que da próxima vez eu compusesse algo mais "animado”. Eu, que já havia trabalhado por um tempo na "animação" das noites nos bares da cidade de Belém, sinceramente nutria um verdadeiro terror da ideia de que o músico existia para "animar" a festa alheia. Apesar de que este sempre fora todo o sentido primeiro da prática seresteira! Na verdade, estava muito feliz em dar vazão à minha inclinação à melancolia que, pouco a pouco, descobria como um impulso interior altamente produtivo em matéria de criação. Porém, no sentido de compreender mais amorosamente a provocação de meu amigo baiano, lembrei-me de uma outra lição/sermão da mais alta sabedoria seresteira que meu pai sempre repetia: o músico tem que tocar para o público, e não para ele mesmo. Quando era um adolescente aprendendo a tocar o instrumento e me aventurando, ainda muito timidamente, a cantar nas serestas de família, essa lição/conselho de meu pai me parecia autoritária e até um pouco cruel. Mas, no embate com meu amigo baiano, estando eu um pouco mais maduro, resolvi deixar meu orgulho de ser-estar melancólico de lado e lhe respondi com um samba:

\section{Amigo Gessé}

Amigo Gessé, me encomendaste um samba
E pra não te dizer não me deparei com uma questão musical

De fundo emocional

Já faz tempo, amigo Gessé, que meu pinho não vê um sol maior

$\mathrm{Ai}$, tem dó, do coração dorido deste compositor menor

Amigo Gessé, tu me conheces

Eu gastava minha vida na roda de samba, na viola era bamba

$\mathrm{Na}$ boemia, onde eu cantava despetalava mulheres

Até o dia que esta ingrata me cravou o beijo do mal, perene punhal

E conheci a imensa dor, leito doce e cruel do amor

Orfeu regressado, me dediquei a cantar

A sagração da nostalgia

Daquele dia que a Bahia me arrancou do peito uma passarada

E era quase nada, era tudo, era toda presença morena

Da violenta quimera em flor

No aprofundamento da conversa com a Bahia, uma experiência concreta com a boemia soteropolitana se mostrou como abertura para uma possibilidade de pensar e transitar com mais humor pelo tema maior do imaginário seresteiro: o mal de amor. Na saída de um espetáculo do qual já nem lembro mais, eu e mais três colegas da mesma turma do doutorado resolvemos nos sentar em um bar qualquer para partilhar de um pequeno momento de prosa regado à cerveja. Em determinado momento, Lara, uma das colegas presentes, cantou alguns versos de um samba seu que achei cruelmente lindo. Ele narrava a história de uma moça que não fazia questão alguma das investidas e esforços de um rapaz dedicado aos ritos do amor romântico. Enquanto ela cantava, eu achava aquela letra deliciosamente perversa e, como estava com o violão no carro, resolvi buscá-lo para acompanhá-la naquele singelo deboche do amor. Tal atitude contrariava fortemente a sole-

\footnotetext{
${ }^{5}$ Letra de composição autoral registrada em caderno pessoal de anotações. Disponível no canal do YouTube "Manifesto Pitágoras", acessível pelo link: https://youtu.be/DXKvv-IaW2U.

${ }^{6}$ Letra de composição autoral registrada em caderno pessoal de anotações. Disponível no canal do YouTube "Manifesto Pitágoras", acessível pelo link: https://youtu.be/gDMUmoszanA.
} 
nidade e a seriedade com que o amor é tratado na tradição da canção seresteira, mas algo me provocava naquele universo que Lara propunha, e dali eu ainda não sabia, mas encontraria uma chave que me permitiria transcender com mais alegria o mal de amor seresteiro. Naquela noite, nós nos reunimos na casa de Lara após sermos basicamente expulsos do bar, em razão da cantoria que já adentrava as horas ditas impróprias por não-seresteiros. Na casa que agora nos acolhia, eu, Lara Couto, Hayaldo Copque e Matheus Schimith passaríamos uma madrugada inteira compondo canções tragicômicas de amores desacertados. Entre essas canções, sem nenhuma modéstia, destaco a obra-prima daquela noite seresteira:

\section{Ela tem namorado}

Vai e volta e agacha e rola

E gira e salta e dança

A frase que não me sai da lembrança

meu fevereiro desmoronado

ela tem namorado.

Vai e volta e agacha e rola

perco tempo fazendo poema

meu fracasso declarado

o meu março desperdiçado

ela tem namorado

Vai e volta e agacha e rola

Ligo, insisto,

filme no cinema já está acabado

meu abril despedaçado

ela tem namorado

passa maio, Ana, Maria, Cristina, Liz e Fabia-

na

essa noite foi bacana

na memória, o seu retrato

ela tem namorado

passa mês, é junho, julho

agosto, é o inverno é o inferno

e não tem agasalho

que aqueça um coração abandonado

ela tem namorado

já fui no terreiro

na igreja, templo budista, sinagoga

fiz retiro de ioga

vi setembro no baralho

ela ainda tem namorado

vai e volta e toda aquela bossa

e eu ainda estou na fossa

a pensar no recado outubro subiu no telhado

ela tem namorado

vai findando o ano

vai novembro, vem dezembro

e eu todo lascado no meu doutorado

meu calendário todo retalhado

ela tem namorado ${ }^{7}$

Seguindo o curso do rio que o samba e meus amigos baianos e da boemia baiana me ajudaram a reconhecer, em uma série de composições me dediquei a imaginar um novo destino para os temas e melodias seresteiras. $\mathrm{Na}$ canção a seguir, uma história de amor desacertado de certo "amigo" inspirou uma canção que re-faz a tradição da canção seresteira, invocando os padrões harmônicos, melódicos e rítmicos do bolero, mas transformando o eu-lírico rigorosamente queixoso em um personagem que narra sua mágoa, embora analise e quase ria de si mesmo enquanto expõe sua ferida. Nessa canção, além da conhecida forma de exposição da mágoa de uma amada diante de um desacerto amoroso, é também explorado um discurso metalinguístico que se dedica à elaboração de imagens que se propõem à tradução de princípios da prática seresteira:

\section{Gastei minha melhor camisa}

Gastei minha melhor camisa

Em nome da brisa que pensei sentir

Nem minha intimidade com o vento

Que é o melhor amigo do arqueiro do amor

Não me livrou de um erro tão banal

Um beijo roubado no carnaval

Não abre precedente

Pr'um flerte sincero, mas consequente

Eu sei que diante do cenário político atual Talvez fosse melhor compor um samba social Mas eu não pude ignorar teus olhos verdes Foste tu que começaste

Agora escute o meu reclame e nunca mais me chame

Sou adepto das práticas da lua

A cidade dorme e eu canto na rua

É minha oração, minha lei, minha ciência, minha religião

Então não me leve a mal, romance pra mim

${ }^{7}$ Letra de composição autoral registrada em caderno pessoal de anotações. Disponível no canal do YouTube "Manifesto Pitágoras", acessível pelo link: https://youtu.be/sYLXAOR75ng. 
era o curso natural

Posso fingir que uma estrela não nasceu e fica tudo igual $^{8}$

Enamorado desastrado, o "amigo", cuja identidade aqui protejo, serviu de inspiração à numerosas investidas na exploração do mal de amor, mas em determinado momento senti que precisava concedê-lo alguma possibilidade de libertação desse tema. É evidente que o mal de amor, enquanto experiência visceral do estilhaçamento amoroso, termina por constituir fonte riquíssima para a produção poética. Essa definitivamente não é uma exclusividade seresteira. Nesse sentido, com a canção abaixo busquei constituir um outro tipo de resposta à experiência do mal de amor, estabelecendo-a quase como um acalanto de um amador desiludido para si mesmo, ao mesmo tempo em que concede ao amor uma respeitosa despedida. Com esta composição, retomo alguma solenidade do tratamento do amor na canção seresteira, mas com a tentativa de preservar certa leveza aprendida em estações anteriores desse manifesto. A canção a seguir pela primeira vez se desprende completamente das formas musicais pré-estabelecidas de gênero, e se expressa na tentativa da constituição de singularidade literária e musical, guardando, contudo, as referências das tradições populares tão caras a meu processo criativo. Nesta canção, a estrutura repetitiva da estrofe tem como referência a estrutura composicional do romance:
Ave-amor
Ave-Amor, dentro em mim
Deixa invernar enfim...
Deixa gelar o sol feroz
Deixa secar os girassóis
Deixa..
Ave-Amor, dentro em mim
Deixa a bruma se formar
Deixa o teu olho esquerdo se cegar

Deixa perder o caminho de casa
Deixa...

Ave-Amor, dentro em mim

Deixa o rio voltar do mar

Deixa a barriga dela des-engravidar

Deixa o tempo regressar

Deixa...

Ave-Amor, dentro em mim

Deixa serenar o vulcão

Deixa o leão serenar o furacão

Deixa a canção chegar no fim

Deixa...

Ave-Amor, dentro em mim

Deixa fenecer o jardim

Deixa esquecer cor e cheiro do jasmim

Deixa calar o alecrim

Alecrim doirou encantando Ave-Amor

Fez-se um sol feroz incendiando girassóis

Foi quando a branca luz fecundou a terra dura

Fez nascer um jardim, no coração dele um jasmim

Mas deixa...

Deixa... ${ }^{9}$

Se o mal de amor e o amor em si podem ser tratados de outro modo, em um caminho passarinho de leveza e desatino, na próxima canção busquei explorar a transcendência do sentido do ato criativo de compor, por meio da imaginação de fragmentos do cotidiano de uma relação erótica entre um eu-lírico-compositor e uma personificação da própria canção, a qual interpreta o papel da amada. Aqui, a seresta enquanto gênero é resgatada na forma de valsa, mas o drama amoroso da tradição da canção seresteira é transfigurado para que o amor da canção e do compositor narre, com ternura, uma história de como acontece a criação:

\section{A canção amanheceu}

Bela, feminina e bela

Tão menina e bela

A canção me acordou com uma flor na boca Uma carinha de louca

\footnotetext{
${ }^{8}$ Letra de composição autoral registrada em caderno pessoal de anotações. Disponível no canal do YouTube "Manifesto Pitágoras", acessível pelo link: https://youtu.be/xFA7rhP6hLY.

${ }^{9}$ Letra de composição autoral registrada em caderno pessoal de anotações. Disponível no canal do YouTube "Manifesto Pitágoras", acessível pelo link: https://youtu.be/x0VBJJ0q0-w.
} 
Um punhal cravado em meu peito

É o amor

E diz que pra ser feliz é preciso acordar E quer tomar café com tapioquinha

E sofre a imensa fome cruel

Não suporta ver no céu o sol sem poder dançar

Bela, feminina e bela

Tão menina e bela

A canção amanheceu

Enroscada ao corpo meu

Como a cobra que morde o rabo seu

Fez de mim o mais sereno arauto do amor ${ }^{10}$

Arauto do amor: talvez seja essa uma das mais nobres sinas do seresteiro. No entanto, para que o seresteiro mereça ser do amor o seu arauto, talvez seja necessário que ele entre em contato com sua amada de dentro, aquela que lhe ensina a sabedoria da delicadeza. Dada sua inclinação aos apaixonamentos, não raro o seresteiro projeta sobre uma mulher real a imagem da amada de dentro. Assim, no caminho da composição, a amada real comumente faz a função da musa, inspirando a criação da canção. Isso eu muito aprendi com aquele "amigo", que também é compositor e seresteiro. No terreno imaginário no qual cultivo meu processo criativo, amada, musa e canção habitam sob muitas formas (frequentemente femininas) o coração do seresteiro-compositor. Tomo tais figuras femininas como manifestações da anima ${ }^{11}$ (outro nome da amada de dentro), que aqui atua tão simplesmente como o guia interior para o mundo do inconsciente, de onde é retirado todo material que dá forma às imagens literárias e melódicas que fazem a canção. Estação musical final desta versão do manifesto, compartilho a canção que constela em poesia, harmonia e melodia manifestação da anima com a qual primeiro eu me conectei: minha mãe. Esta é uma canção que tenta restituir à mãe o lugar de fonte fundamental, cacimba primeira dos tempos, regente primordial da criação. Uma vez mais, a tradição da canção seresteira é retomada na escolha da valsa como gênero, a partir do qual foi criada esta composição que evoca e transporta para um lugar talvez estranho à tradição o ritual amoroso da serenata:

\section{Serenata para a mãe}

Noite escura, espera que apura

O sabor cruel do desamor

Abre tua porta, não demora

Tens o dom de desfazer o medo e a dor

Conta-se que no começo o rio e o arvoredo eram simplesmente som

E foi teu tom que fez do mundo essa canção

Não havia cachoeira, chuva não havia, foi tua melodia, mãe

Que fez nascer o mundo, o amor, o estar e o ser

Por isso se preciso vou arrancar

Com minhas próprias mãos o coração do teu agressor

Mesmo que ele seja eu, mesmo que seja meu pai

Não haverá perdão

Noite alta, palavra me falta pra dizer

Pudera ainda eu ser

A criança pura que murmura

A verdadeira declaração de amor ${ }^{12}$

\footnotetext{
${ }^{10}$ Letra de composição autoral registrada em caderno pessoal de anotações. Disponível no canal do YouTube "Manifesto Pitágoras", acessível pelo link: https://youtu.be/COrcASkVaso.

${ }^{11}$ A noção de anima a qual me refiro tem como referência primária a teoria de Carl Gustav Jung sobre a psique humana. Nas palavras de uma de suas alunas e principais comentadoras: "Anima é a personificação de todas as tendências psicológicas femininas na psique do homem - os humores e sentimentos instáveis, as intuições proféticas, a receptividade ao irracional, a capacidade de amar, a sensibilidade à natureza e, por fim, mas não menos importante, o relacionamento com o inconsciente." (VONFRANZ, 2008, pp. 234-235). Dessa percepção, registro a ressalva de que se trata de uma teoria elaborada num tempo anterior à reflexão sobre papeis de gênero. No entanto, como instrumental analítico que serve à leitura simbólica, é interessante notar a representação da anima como intermediário que conecta um "eu" a seus conteúdos mais densos, o que numa abordagem poética do processo criativo aqui discutido é considerado um gesto criador determinante. ${ }^{12}$ Letra de composição autoral registrada em caderno pessoal de anotações. Disponível no canal do YouTube "Manifesto Pitágoras", acessível pelo link: https://youtu.be/f9zmkI6VbXM.
} 


\section{Manifesto}

Da boca do seresteiro brotou uma noturna e flamejante flor.

Nesse instante, do coração da cidade uma revoada de pássaros varou a madrugada cintilando estrelas. Voam para o Norte, onde é sempre verão: é a canção

Nunca se fez sol maior tão noturno quanto aquele que vibra no interior da canção de amor mais dolente. Façam silêncio. $O$ mundo está ruindo e a natureza pede a sua paga. Dolorosa.

A lâmina do homem interrompeu o destino vertical da árvore. Disso, o violão, antes de sê-lo, é uma árvore morta. O violão quando chora, chove. Assim a morte fecunda a terra. Daí a responsabilidade mística daquele que empunha morte traduzir-se no dever ancestral de fazer florescer a terra: corpo-ventre-coração maior do mundo.

Da boca flamejante do noturno seresteiro brotou uma flor.

A cidade está ávida de luz. A cidade tem fome, a cidade tem sede. O medo lhe gela a espinha na hora escura do deserto ruidoso em que ela mora. Habitam seu corpo animais mecânicos de toda sorte: animais bebedores de diesel, cobre, chumbo e luz elétrica. Eles não dormem. Perturbam o sono da cidade que, ainda assim, sonha.

Flamejante, da boca da noturna flor brotou um seresteiro.

Cantai o amor!

Porque o tempo responde favorável ao desejo ardente.

Cantai o amor!

Porque o manto místico da seresta há de pousar sobre a cabeça de cada alma inclinada à festa.

\section{Cantai o amor!}

Porque urge na aurora desses tempos difíceis a imperiosa necessidade de re-fazer mitos e ritos da lua.

Cantai o amor!

Sublime eleição de caminho, abrigo e verdade. 


\section{REFERÊNCIAS}

FONSECA, Wilson. Meu baú mocorongo: Pesquisas, recordações e reflexões sobre a vida histórica e sociocultural santarena. Belém: SECULT/SEDUC, 2006.

GUARRAMUÑO, Florencia. Frutos estranhos: sobre a inespecificidade na estética contemporânea. Tradução Carlos Nougué. Rio de Janeiro: Rocco, 2014.

SALLES, Vicente. A Modinha no Grão-Pará: estudos sobre ambientação e (re) criação da Modinha no Grão-Pará. Belém: SECULT/IAP/AATP, 2005.

SÁNCHEZ, José A. Dramaturgia em el campo expandido. Disponível em: $<$ http://blog.uclm.es/joseasanchez/files/2017/12/2011.-Dramaturgia-en-el-campo-expandido.pdf $>$. Acesso em 17 de fevereiro de 2018.

VON FRANZ, Marie-Louise. O processo de individuação. In: JUNG, Carl Gustav et al. O homem e seus símbolos. Concepção e organização de Carl Gustav Jung. Tradução de Maria Lúcia Pinho. 2. ed. São Paulo: Nova Fronteira, 2008.

ZUMTHOR, Paul. Introdução à poesia oral. Tradução de Jerusa Pires Ferreira, Maria Lúcia Diniz Pochat, Maria Inês de Almeida. Belo Horizonte: Editora UFMG, 2010. 


\begin{abstract}
This paper is based on an introspection, followed by a script with dramaturgical aims, resulting from short stories, thoughts and daydreams intertwine with songs composed in the doctoral research process. In this article, the poetical narrative materializes imaginaries from the seresteiros. This materialization attempts to help the reader enter such imaginaries. Finally, it also aims at producing a creative evaluation of that tradition and proposes alternative roads.
\end{abstract}

\title{
Keywords
}

Seresta. Poetics of the imaginary. Expanded dramaturgy.

\section{Resumen}

Este artículo se basa en una reflexión, seguida de un texto que se pretende dramatúrgico y que reune historias, pensamientos y devaneos. Lo anterior, entrecruzado por una serie de canciones compuestas a lo largo del proceso de investigación doctoral. La elaboración poética es pensada como una materialidad a partir de la cual es posible transitar por el imaginario de la seresta. Finalmente, el articulo procura producir una especie de evaluación creativa de esta tradición y proponer destinos alternativos para ella.

\section{Palabras clave}

Seresta. Poéticas del imaginario, Dramaturgia expandida. 